\title{
Actor and partner effects of coping on adjustment in couples undergoing assisted reproduction treatment
}

\begin{abstract}
BACKGROUND
Infertility is a shared experience as it affects both partners. However, mutual dependencies between coping and adjustment at the couple level remain to be fully elucidated. The study attempted to address this issue using the Actor-Partner Interdependence Model (APIM) to examine the actor effect (the extent to which an individual's score on coping predicted their own level of depressive symptoms and life purpose) and the partner effect (the extent to which an individual's score on coping predicted the level of adjustment in the partner) in couples undergoing assisted reproduction treatment (ART).
\end{abstract}

\section{PARTICIPANTS AND PROCEDURE}

Coping strategies, depressive symptoms, and life purpose were assessed among 31 married couples (aged 27-38 years) undergoing ART. The Brief COPE, CES-D, and PIL questionnaires were used. Data were analyzed by multilevel modeling (MLM)

\section{RESULTS}

The results of MLM indicated that focus on positive and active coping had an actor effect with depressive symp-

\begin{abstract}
toms and life purpose, respectively. The actor effect of evasive coping on depression was moderated by gender and significant only in women. The partner effect was demonstrated for evasive coping, social support seeking, and substance use - the first two were gender moderated and significant in men.
\end{abstract}

\section{CONCLUSIONS}

Coping efforts in the couple during infertility treatment are not only associated with the individual but also the partner's adjustment to that situation. Although the focus on positive and active coping was associated with individual benefits, other coping strategies which have the function of a protective buffer may also result in the occurrence of side effects, especially in females.

\section{KEY WORDS}

coping behavior; depressive symptoms; life purpose; infertile couples; multilevel modeling

ORGANIZATION - University of Social Sciences and Humanities, Warsaw, Poland

aUthors' Contributions - A: Study design - B: Data collection - C: Statistical analysis - D: Data interpretation .

E: Manuscript preparation · F: Literature search · G: Funds collection

CORRESPONDING AUtHOR - Aleksandra Kroemeke, Ph.D., University of Social Sciences and Humanities,

19/31 Chodakowska Str., 03-815 Warsaw, Poland, e-mail: akroemeke@swps.edu.pl

TO CITE THIS ARTICLE - Kroemeke, A., \& Kubicka, E. (2017). Actor and partner effects of coping on adjustment in couples undergoing assisted reproduction treatment. Health Psychology Report, 5(4), 296-303. doi: https://doi.org/10.5114/ hpr.2017.67853

RECEIVED 05.09.2016 · REVIEWED 04.10.2016 · ACCEPTED 26.10.2016 · PUBLISHED 12.06.2017 


\section{BACKGROUND}

Infertility is defined as "failure to achieve a successful pregnancy after 12 or more months of regular unprotected sexual intercourse" (Zegers-Hochschild et al., 2009, p. 1523). According to the World Health Organization, 48.50 million couples worldwide were infertile in 2010, and the number of infertile couples has remained constant since 1990 in most regions of the world (Mascarenhas, Flaxman, Boerma, Vanderpoel, \& Stevens, 2012). In Poland, infertility has been estimated to affect $20 \%$ of couples in the reproductive age group (Kuczyński et al., 2012). Out of them, approximately $40 \%$ seek general healthcare and $60 \%$ undergo specialist diagnostic testing and treatment, including assisted reproduction technologies. Unintended infertility may be the cause of emotional problems (anxiety, sadness, anger) or may negatively affect one's self-beliefs (guilt, shame, worthlessness), relations with the partner (satisfaction with the relationship), and the global terms beliefs (loss of purpose) (Dembińska, 2016; Greil, Slauson-Blevins, \& McQuillan, 2010; Podolska \& Bidzan, 2011). The process of assisted reproduction treatment (ART) itself is also a source of stress and elevated anxiety, or even depression (Olivius, Friden, Borg, \& Bergh, 2004). In other words, it is an experience which - according to the most common definition of stress (Lazarus \& Folkman, 1984) - may be perceived as a stressful situation, which requires coping efforts from an individual, and whose aim is to improve the situation or well-being. What is more, fertility and its treatment is a couple-level stressor, as it always affects both partners. Well-being and ways of coping in one partner may impact the same condition and mechanisms in the other. The Actor-Partner Interdependence Model (APIM) presents the scheme of a dyadic relationship (Kenny, Kashy, \& Cook, 2006). APIM differentiates between actor effects and partner effects. The former refer to an individual's influence of the predictor variable on the same individual's score of the outcome variable, while the latter represent cross-person cross-variable paths, i.e. the effect of one partner's predictor variable on the other partner's outcome variable. So far, the literature has offered a limited number of studies on couples dealing with infertility or during infertility-related therapy. They have indicated that higher active-avoidance and passive-avoidance coping and lower meaning-based coping are associated with one's own (actor effect) and the spouse's (partner effect) baseline (Peterson, Pirritano, Christensen, \& Schmidt, 2008), short- and long-term distress (Peterson et al., 2009); the use of higher meaning-based coping, on the other hand, had a positive actor effect with marital benefit over 5 years (Peterson, Pirritano, Block, \& Schmidt, 2011). Other studies have dealt with similarity and compensatory interactions in couples. Berghuis and Stanton (2002) reported a compensatory effect of emotional- approach coping: an unfavorable high level of coping in women compensated for its low level in men, thus preventing the occurrence of depression in the former. A relatively small amount of data on gender differences in actor and partner effects (Peterson et al., $2009,2011)$ suggested that spouses may be more similar than different in their coping efforts with infertility and during ART.

The aim of the study was to test the actor and partner effects of coping strategies on the adjustment - depressive symptoms and life purpose - in couples undergoing ART. Namely, the effect of each partner's coping on their own adjustment, as well as the effect of the wife's coping on the husband's depressive symptoms and life purpose and the effect of the husband's coping on the wife's depressive symptoms and life purpose were tested. To the best of our knowledge, this is the first study of infertile couples in Poland to treat a couple as a unit of analysis and to apply the APIM model. Also, it is the first attempt to search not only for predictors of depression but also of life propose in both partners. Until now, various researchers have focused predominantly on anxiety, depression, and distress in these settings (Berghuis \& Stanton, 2002; Lawson et al., 2014; Peterson et al., 2008, 2009), whereby they were pathogenetically oriented. This study implements the salutogenic approach by searching for predictors of positive indices of adaptation to ART as well.

\section{PARTICIPANTS AND PROCEDURE}

\section{PARTICIPANTS}

The sample was composed of 31 married couples, aged 27-38 years (women: $M=31.97, S D=2.98$; men: $M=33.37, S D=2.12$ ) during ART. Mean duration of marriage was 6.55 years $(S D=1.99$, range: 4-14 years). Most participants had higher education (women: 97.00\%, men: 90.00\%) and declared average socioeconomic status $(93.00 \%)$. Mean duration of infertility treatment had been 2.63 years $(S D=2.03$, range: $0.20-8.00$ years), currently by monitoring ovulation (19.40\%, mean $2.33 \pm 1.51$ cycles, range: $1-5)$, intrauterine insemination (54.80\%, mean $2.00 \pm 0.86$ cycles, range: $1-4)$, and in vitro fertilization $(25.80 \%$, mean $2.88 \pm 0.99$ cycles, range: $2-5$ ).

The study protocol was approved by the Local Ethics Committee. Written informed consent was obtained from all participants. Recruitment for the study took place before a standard control visit at a public fertility clinic. In total, 190 patients (95 couples) received envelopes with information about the study and the questionnaires, as well as pre-addressed stamped return envelopes. The participants were instructed to complete the questionnaires independently. The response rate was $33.00 \%$.
Actor and partner effects of coping on adjustment in infertile couples 


\section{MEASURES}

Depressive symptoms. Depressive symptoms were measured using the Polish version of the Centre for Epidemiological Studies Depression Scale (CES-D) (Radloff, 1977; Ziarko, Kaczmarek, \& Haładziński, 2013), assessed on a four-point scale, from 0 (rarely or never) to 3 (often). Higher result indicated a greater number of depressive symptoms. Cronbach's $\alpha$ was .93 .

Life purpose. Meaning in life was measured us-

Aleksandra Kroemeke, Ewelina Kubicka ing the Polish version of the abbreviated (6-item) version of the Purpose in Life (PIL) test (Crumbaugh \& Maholick, 1964; Życińska \& Januszek, 2011), assessed on a seven-point scale with different anchoring points for each item. A higher result indicated a greater sense of meaning in life. Cronbach's $\alpha$ was .89 .

Coping strategies. Coping was assessed with the Polish version of the abbreviated situational version of COPE (Brief COPE) (Carver, 1997). The participants rated the extent to which they undertook each behavior in a stressful situation (related to infertility) on a four-point scale from 1 (I haven't been doing this at all) to 4 (I've been doing this a lot). Originally, Brief COPE consists of 14 subscales (with only 2 items per scale). Due to their low reliability in this study, and following the suggestions of Carver, Scheier, and Weintraub (1989), as well as previous results on the dimensionality of the Brief COPE (Monzani et al., 2015), a second-order exploratory factor analysis was performed. Five higher-order factors were identified and analyzed further: Focus on Positive (consists of Acceptance, Positive reframing, Humor; $\alpha=.76$ ), Active Coping (Active coping, Planning, Self-distraction; $\alpha=.72$ ), Social Support Seeking (Use of emotion support, Use of instrumental support, Religion; $\alpha=.78$ ), Evasive Coping (Selfblame, Denial, Venting, Behavioral disengagement; $\alpha=.71$ ), and Substance Use (Substance use; $\alpha=.99$ ). A higher result in each scale indicated greater coping efforts in a particular type.

Table 1

Descriptive statistics of the measured variables $(N=31$ couples $)$

\begin{tabular}{lcccccc}
\hline & \multicolumn{3}{c}{ Women } & \multicolumn{3}{c}{ Men } \\
\cline { 2 - 7 } & $M$ & $S D$ & $\min -\max$ & $M$ & $S D$ & $\min -$ max \\
\hline Depressive symptoms & 1.36 & 0.43 & $0.55-2.00$ & 0.68 & 0.34 & $0.20-1.40$ \\
Life purpose & 5.16 & 0.68 & $4.00-6.17$ & 5.92 & 0.70 & $4.00-7.00$ \\
Focus on positive & 1.80 & 0.45 & $1.00-3.00$ & 2.40 & 0.54 & $1.33-3.50$ \\
Active coping & 3.58 & 0.31 & $2.80-4.00$ & 3.70 & 0.44 & $2.40-4.00$ \\
Social support seeking & 2.34 & 0.46 & $1.17-3.17$ & 1.83 & 0.53 & $1.00-3.00$ \\
Evasive coping & 2.42 & 0.36 & $1.88-3.00$ & 1.99 & 0.46 & $1.13-2.88$ \\
Substance use & 1.27 & 0.44 & $1.00-2.00$ & 1.71 & 0.53 & $1.00-3.00$ \\
\hline
\end{tabular}

Multilevel modeling (MLM) from the pairwise dataset (couples were treated as groups of two people) in SPSS version 23 was performed in order to examine the actor and partner effects of coping strategies on individual adaptation of the spouses (depressive symptoms and life purpose). Multilevel modeling is considered to be one of the best methods to examine the effects in APIM (Kenny et al., 2006). Two separate models, one for depressive symptoms and one for life purpose, were created. Each model included all five coping strategies. In addition, the main effects of treatment time and gender, as well as gender interactions with actor and partner effects, were examined. Predictors were grand mean centered. Other controlled variables were not significantly associated with adjustment indicators, so they were not included in the models. Pseudo $R^{2}$, defined as 1 - (estimates of the variance and covariance of the full model/estimates of the variance and covariance from the null model), was calculated to determine the estimate of variance explained by the predictors separately for wives and husbands (Kenny et al., 2006). Goodness of fit for the models was based on the -2 restricted log likelihood ratio and the Akaike information criterion (AIC), and Bayesian information criterion (BIC). The model with lower AIC, BIC and -2 restricted log likelihood values indicated a better fit (Kenny et al., 2006).

\section{RESULTS}

Descriptive statistics are presented in Table 1. Women reported significantly higher social support seeking coping $(U=218.50, p<.001)$, and evasive coping $\left(t_{60}=4.13, p<.001\right)$, as well as lower focus on positive $(U=182.00, p<.001)$, active coping $(U=330.00$, $p=.029)$, and substance use coping $(U=280.00$, $p<.001)$ as compared to men. Partial Pearson cor- 
relations, controlling for gender, indicated significant relations only between actor and partner focus on positive $(r=.53, p<.001)$ and evasive coping $(r=.27$, $p=.035)$.

The MLM results showed significant actor effects of focus on positive coping on the depressive symptoms and active coping on the life purpose (Table 2). The findings demonstrated that these types of coping were related to better adjustment (lower depression, higher life purpose). There was also a significant interaction between the actor effect of evasive coping and gender, indicating that this effect is gender-de-

Table 2

Results of MLM - APIMs for depression and life purpose $(N=31$ couples $)$

\begin{tabular}{|c|c|c|c|c|}
\hline \multirow[t]{3}{*}{ Model } & \multicolumn{4}{|c|}{ Adjustment } \\
\hline & \multicolumn{2}{|c|}{ Depressive symptoms } & \multicolumn{2}{|c|}{ Life purpose } \\
\hline & $B$ & $S E$ & $B$ & $S E$ \\
\hline Intercept & $.89^{* * *}$ & .15 & $5.26^{* * *}$ & .34 \\
\hline \multicolumn{5}{|l|}{ Focus on positive } \\
\hline Actor & $-.47^{*}$ & .20 & .25 & .23 \\
\hline Partner & .17 & .20 & .26 & .19 \\
\hline \multicolumn{5}{|l|}{ Active coping } \\
\hline Actor & -.11 & .14 & $.59^{* *}$ & .21 \\
\hline Partner & -.19 & .14 & -.23 & .18 \\
\hline \multicolumn{5}{|l|}{ Social support seeking } \\
\hline Actor & -.08 & .10 & -.25 & .15 \\
\hline Partner & .16 & .11 & -.16 & .14 \\
\hline \multicolumn{5}{|l|}{ Evasive coping } \\
\hline Actor & .13 & .13 & -.12 & .22 \\
\hline Partner & .01 & .13 & $.56^{*}$ & .21 \\
\hline \multicolumn{5}{|l|}{ Substance use } \\
\hline Actor & -.21 & .13 & .18 & .19 \\
\hline Partner & .12 & .13 & $.53^{* *}$ & .17 \\
\hline Time & $.07^{*}$ & .03 & $-.28 * * *$ & .06 \\
\hline Gender $^{a}$ & .11 & .16 & .24 & .14 \\
\hline Actor evasive coping $\times$ gender $^{b}$ & $-.33^{*}$ & .13 & & \\
\hline Partner social support seeking $\times$ gender $^{b}$ & & & $-.41^{*}$ & .18 \\
\hline Partner evasive coping $\times$ gender $^{\mathrm{b}}$ & & & $.42^{*}$ & .21 \\
\hline-2 Restricted log likelihood full model & \multicolumn{2}{|c|}{46.62} & \multicolumn{2}{|c|}{65.65} \\
\hline AIC full model/null-model ${ }^{c}$ & \multicolumn{2}{|c|}{$52.62 / 96.14$} & \multicolumn{2}{|c|}{$71.65 / 152.50$} \\
\hline BIC full model/null-model ${ }^{c}$ & \multicolumn{2}{|c|}{$57.61 / 104.64$} & \multicolumn{2}{|c|}{$76.64 / 161.01$} \\
\hline Pseudo $R^{2}$ (women/men) & \multicolumn{2}{|c|}{$74 \% / 50 \%$} & \multicolumn{2}{|c|}{$54 \% / 82 \%$} \\
\hline
\end{tabular}

Note. AIC - Akaike information criterion, BIC - Bayesian information criterion.

${ }^{\mathrm{a}}$ Gender was coded: 1 (men), -1 (women), ${ }^{\mathrm{b}}$ Only significant interactions are presented, ${ }^{\mathrm{c}}$ Full model - model with all predictors, null model - model with intercept only; ${ }^{*} p<.05,{ }^{* *} p<.01,{ }^{* *} p<.001$. pendent. On further analysis, the two-intercept MLM found that the evasive actor effect on the depressive symptoms was significant only in women and was positive $(B=.46, S E=.19, p=.025)$.

Regarding partner effects, evasive coping and substance use were related to higher life purpose. Two partner effects were moderated by gender: social support seeking and evasive coping (Table 2). Additional analysis (the two-intercept MLM) demonstrated that a positive partner effect of evasive coping $(B=.98, S E=.26, p=.002)$ and a negative partner effect of social support seeking $(B=-.57, S E=.21$, effects of coping on adjustment in infertile couples 
$p=.015)$ on life purpose were significant only in men. Additionally, there was a significant main effect of time of treatment, i.e. longer time of treatment was related to poorer adjustment - higher depressive symptoms and lower life purpose.

\section{DISCUSSION}

Aleksandra

Kroemeke,

Ewelina Kubicka

The aim of the study was to investigate the relationship between coping strategies and adjustment of couples undergoing ART. APIM is the most reliable tool to describe the relations in a couple. APIM allows one to determine both the actor effects (relationship between two variables in one person) and the partner effect (relationship between two variables cross-person). In general, two significant actor effects, two partner effects, and three gender-moderated effects have been observed. Conditional models (with predictors) fitted the data better than empty models (without predictors; see changes in AIC and BIC). The percentage of the explained variance of adjustment in both women and men was relatively high (from $50 \%$ to over $80 \%$ ). The obtained results are compatible with previous literature reports.

Regarding the actor effects, the focus on positive was associated with a lower depression level, whereas active coping was associated with higher life purpose. Both findings are consistent with previous studies (Berghuis \& Stanton, 2002; Guo, Gan, \& Tong, 2013; Jim, Richardson, Golden-Kreutz, \& Andersen, 2006; Kraaij, Garnefski, Schroevers, Weijmer, \& Helmerhorst, 2010; Wang, Lightsey, Pietruszka, Uruk, \& Wells, 2007). In light of the fact that this study was cross-sectional, it is challenging to draw unambiguous conclusions on the relationships between the variables. On one hand, acceptance of the status quo, its positive reframing, planning and direct action to solve the problem may result in better adjustment to the difficult experience of ART, which has been confirmed by longitudinal studies (Berghuis \& Stanton, 2002). These strategies are often described as 'adaptive' (Carver et al., 1989). On the other hand, better adjustment fewer depressive symptoms and higher sense of purpose - may promote such actions. Purpose in life is believed to be the driving force behind any activity (Ryff \& Singer, 1998), while neutral or positive effects promote focus on the positive sides, and build and broaden the resources (Fredrickson, 2001). Notably, strategies which may be described as instrumental (problem-focused) were associated with the cognitive component of well-being, i.e. life purpose, whereas constructive emotion-focused strategies were linked with depressive symptoms (emotional component of well-being). Regardless of the direction, the relations were the same for women and men.

Gender moderated the actor effect of evasive coping on depression. Detailed analysis found the relationship between evasive coping and depressive symptoms to be significant only in the group of females. Denial, self-blame, and venting were promoting factors for depressive symptoms in women, which has also been reported by numerous other authors (Berghuis \& Stanton, 2002; Gourounti et al., 2012; Lawson et al., 2014). These strategies are often described as 'dysfunctional' (Carver et al., 1989). Obviously, it would not be prudent to exclude the possibility that depressive mood promoted the focus on negative emotions or their suppression. The relations between the variables are reciprocal. Possibly, the existence of that relationship in women is associated with a tendency to experience more depressive symptoms (Angst et al., 2002; Musa et al., 2014), as well as to use 'palliative coping' (Jordan \& Revenson, 1999; Matud, 2004), which might suggest that the relation has clinical effects once a certain level has been reached. Factors which protect males from unfavorable effects of evasive coping and/or depressive symptoms remain to be fully elucidated.

As for the partner effects, evasive coping and substance use of one partner were positively correlated with life purpose of the other partner, although this first relation was moderated by gender. Additionally, gender differences were observed for seeking social support. Generally, higher sense of purpose in one spouse, especially in men, was associated with maladaptive coping strategies of the other spouse. An association between evasive coping and social support seeking and life purpose was observed only in men: higher evasive coping and weaker social support seeking in women were correlated with higher sense of purpose in men. The result, albeit paradoxical, is consistent with the mixed results on effects of partner coping (Revenson \& DeLongis, 2011). Several different hypotheses can be proposed to explain these relationships. First of all, avoidance coping (including substance use), self-blame, denial, or not seeking support may be considered as 'protective buffering coping' (hiding concerns from the partner and not disclosing personal worries to protect the partner) (Coyne \& Smith, 1991). Lack of open communication and avoidance of difficult topics or emotions may be the reasons why the other partner feels unburdened and the relationship is seemingly good, thus allowing one to maintain a high sense of purpose. However, the literature had demonstrated that relationship protective behaviors may result in psychological consequences for the partner who undertakes them, which was probably the case in our study. The relations of women's evasive coping with adjustment might suggest that such coping strategies would be more beneficial for their partners (higher sense of purpose) rather than the women themselves. In fact, in the latter case these strategies correlated with greater depressive symptoms. Another explanation might be connected with gender stereotypes: the feeling of control (a pro- 
moting factor for life purpose) in men is achieved by avoidance of threatening information (Revenson \& DeLongis, 2011), in this case the women's evasive coping (additionally, the correlation between evasive coping of both spouses was positive). Possibly, a partner with a high sense of purpose reinforces the abovementioned behaviors in his female partner. Thus, the third hypothesis is associated with the esteem enhancement theory (Batson \& Powell, 2003) - when support and care of the 'weaker' partner reinforce one's own assets. Importantly, coping congruence, marital satisfaction, or past spousal supportiveness may modify the relations between partner coping and adjustment (Hagedoorn et al., 2011; Revenson \& DeLongis, 2011), so these variables should be taken into consideration in future studies.

Furthermore, an unfavorable relationship was detected for treatment duration and couple adjustment to ART, which is consistent with other studies (Greil et al., 2010). An inter-correlation was found between life purpose and focus on positive and evasive coping of the spouses, which might indicate that they may reinforce both their resources and deficits. Also, as previously reported in the literature (Jordan \& Revenson, 1999), women were found to apply significantly more strategies described as 'maladaptive', with the exception of support seeking and substance use, as compared to men.

The MLM results did not confirm gender differences in adjustment during ART, which is in contrast to previous findings (Musa et al., 2014), and may be connected with the limitations of our study. Due to the low $(33 \%)$ response rate, partly due to the dyadic nature of the study and partly due to the mail survey formula, generalization of the study results is limited. The sample size can also be considered small, particularly in terms of the number of couples $(N=31)$. Only the patients of a public infertility center, with a government-recommended in vitro program, were recruited. Access to a larger and more diverse population (private programs) was restricted by the private centers, and the partner clinic had little patient rotation. Furthermore, as mentioned above, the study was cross-sectional in nature, which does not allow cause-effect conclusions about the investigated relationships to be drawn. Regardless, to the best of our knowledge, this study is the first attempt to determine mutual relations between coping and adjustment in couples facing infertility.

\section{CONCLUSIONS}

Coping efforts in a wife-husband couple have been demonstrated to be associated not only with one's own emotional and negative (depressive symptoms) and cognitive and positive adjustment (life purpose), but also partner's adjustment to this stressful situ- ation. Some efforts, e.g. focus on positive and active coping, result only in actor effects and benefits. Others, described as protective buffering coping, demonstrate a partner effect, while their effectiveness remains debatable, e.g. evasive coping, which has a two-fold effect - negative for women and positive for men.

The obtained results include a valuable tip for practical application. It is important to reinforce the focus on positive and active coping strategies in both women and men undergoing ART. In the case of maladaptive coping, the action should be initiated only after couple-specific reinforcement mechanisms are identified and should aim at improving the well-being of both partners. In the case of men, it may be connected with activation of other resources and predictors of life purpose than non-adaptive coping of their partners.

\section{ACKNOWLEDGEMENTS}

The study was supported by the Polish Ministry of Science and Higher Education core funding for Statutory Research in SWPS University of Social Sciences and Humanities, Faculty of Psychology, 221516/E-560/S/2016.

\section{ReferenCES}

Angst, J., Gamma, A., Gastpar, M., Lépine, J. P., Mendlewicz, J., \& Tylee, A. (2002). Gender differences in depression. Epidemiological findings from the European DEPRES I and II studies. European Archives of Psychiatry and Clinical Neuroscience, 252, 201-209. doi: 10.1007/s00406-002-0381-6

Batson, C. D., \& Powell, A. A. (2003). Altruism and prosocial behavior. In T. Millon \& M. J. Lerner (eds.), Handbook of psychology. Volume 5. Personality and social psychology (pp. 463-484). Hoboken, New Jersey: John Wiley \& Sons, Inc.

Berghuis, J. P., \& Stanton, A. L. (2002). Adjustment to a dyadic stressor: a longitudinal study of coping and depressive symptoms in infertile couples over an insemination attempt. Journal of Consulting and Clinical Psychology, 70, 433-438.

Carver, C. S. (1997). You want to measure coping but your protocol's too long: consider the brief COPE. International Journal of Behavioral Medicine, 4, 92-100. doi: 10.1207/s15327558ijbm0401_6

Carver, C. S., Scheier, M. F., \& Weintraub, J. K. (1989). Assessing coping strategies: a theoretically based approach. Journal of Personality and Social Psychology, 56, 267-283.

Coyne, J. C., \& Smith, D. A. (1991). Couples coping with a myocardial infarction: a contextual perspective on wives' distress. Journal of Personality and Social Psychology, 61, 404-412.
Actor and partner effects of coping on adjustment in infertile couples 
Crumbaugh, J. C., \& Maholick, L. T. (1964). An experimental study in existentialisam: The psychometric approach to Frankl's concept of noogenic neurosis. Journal of Clinical Psychology, 20, 200-207.

Dembińska, A. A. (2016). Psychological determinants of life satisfaction in women undergoing infertility treatment. Health Psychology Report, 4, 146-158. doi: 10.5114/hpr.2016.56617

Fredrickson, B. L. (2001). The role of positive emotions in positive psychology. The American Psychologist, 56, 218-226.

Aleksandra

Kroemeke,

Ewelina Kubicka

Gourounti, K., Anagnostopoulos, F., Potamianos, G., Lykeridou, K., Schmidt, L., \& Vaslamatzis, G. (2012). Perception of control, coping and psychological stress of infertile women undergoing IVF. Reproductive Biomedicine Online, 24, 670-679. doi: 10.1016/j.rbmo.2012.03.002

Greil, A. L., Slauson-Blevins, K., \& McQuillan, J. (2010). The experience of infertility: a review of recent literature. Sociology of Health \& Illness, 32, 140-162. doi: 10.1111/j.1467-9566.2009.01213.x

Guo, M., Gan, Y., \& Tong, J. (2013). The role of meaning-focused coping in significant loss. Anxiety, Stress, and Coping, 26, 87-102. doi: 10.1080/10615806.2011.627507

Hagedoorn, M., Dagan, M., Puterman, E., Hoff, C., Meijerink, W. J. H. J., Delongis, A., \& Sanderman, R. (2011). Relationship satisfaction in couples confronted with colorectal cancer: the interplay of past and current spousal support. Journal of Behavioral Medicine, 34, 288-297. doi: 10.1007/ s10865-010-9311-7

Jim, H. S., Richardson, S. A., Golden-Kreutz, D. M., \& Andersen, B. L. (2006). Strategies used in coping with a cancer diagnosis predict meaning in life for survivors. Health Psychology, 25, 753-761. doi: org/10.1037/0278-6133.25.6.753

Jordan, C., \& Revenson, T. A. (1999). Gender differences in coping with infertility: a meta-analysis. Journal of Behavioral Medicine, 22, 341-358.

Kenny, D. A., Kashy, D. A., \& Cook, W. L. (2006). Dyadic Data Analysis. New York, NY: Guilford Press.

Kraaij, V., Garnefski, N., Schroevers, M. J., Weijmer, J., \& Helmerhorst, F. (2010). Cognitive coping, goal adjustment, and depressive and anxiety symptoms in people undergoing infertility treatment: a prospective study. Journal of Health Psychology, 15, 876-886. doi: 10.1177/1359105309357251

Kuczyński, W., Kurzawa, R., Oszukowski, P., Pawelczyk, L., Poreba, R., Radowicki, S., Szamatowicz, M., \& Wołczyński, S. (2012). Polish Gynecological Society and Polish Society for Reproductive Medicine recommendations for the diagnosis and treatment of infertility. Ginekologia Polska, 83, 149-154.

Lawson, A. K., Klock, S. C., Pavone, M. E., Hirshfeld-Cytron, J., Smith, K. N., \& Kazer, R. R. (2014). Prospective study of depression and anxiety in

female fertility preservation and infertility patients. Fertility and Sterility, 102, 1377-1384. doi: 10.1016/j.fertnstert.2014.07.765

Lazarus, R. S., \& Folkman, S. (1984). Stress, Appraisal, and Coping. New York: Springer Publishing Company.

Mascarenhas, M. N., Flaxman, S. R., Boerma, T., Vanderpoel, S., \& Stevens, G. A. (2012). National, regional, and global trends in infertility prevalence since 1990: a systematic analysis of 277 health surveys. PLoS Medicine, 9, e1001356. doi: 10.1371/ journal.pmed.1001356

Matud, M. P. (2004). Gender differences in stress and coping styles. Personality and Individual Differences, 37, 1401-1415. doi: 10.1016/j.paid.2004.01.010

Monzani, D., Steca, P., Greco, A., Addario, M. D., Cappelletti, E., \& Pancani, L. (2015). The situational version of the Brief COPE: Dimensionality and relationships with goal-related variables. Europe's Journal of Psychology, 11, 295-310. doi: 10.5964/ ejop.v11i2.935

Musa, R., Ramli, R., Yazmie, A.W. A., Khadijah, M. B. S., Hayati, M. Y., Midin, M., Nik Jaafar, N. R., Das, S., Sidi, H., \& Ravindran, A. (2014). A preliminary study of the psychological differences in infertile couples and their relation to the coping styles. Comprehensive Psychiatry, 55 Suppl 1, S65-69. doi: 10.1016/j.comppsych.2013.01.001

Olivius, C., Friden, B., Borg, G., \& Bergh, C. (2004). Why do couples discontinue in vitro fertilization treatment? A cohort study. Fertility and Sterility, 81, 258-261. doi: 10.1016/j.fertnstert.2003.06.029

Peterson, B. D., Pirritano, M., Block, J. M., \& Schmidt, L. (2011). Marital benefit and coping strategies in men and women undergoing unsuccessful fertility treatments over a 5-year period. Fertility and Sterility, 95, 1759-1763.e1. doi: 10.1016/j.fertnstert.2011.01.125

Peterson, B. D., Pirritano, M., Christensen, U., Boivin, J., Block, J., \& Schmidt, L. (2009). The longitudinal impact of partner coping in couples following 5 years of unsuccessful fertility treatments. $\mathrm{Hu}$ man Reproduction, 24, 1656-1664. doi: 10.1093/ humrep/dep061

Peterson, B. D., Pirritano, M., Christensen, U., \& Schmidt, L. (2008). The impact of partner coping in couples experiencing infertility. Human Reproduction, 23, 1128-1137. doi: 10.1093/humrep/den067

Podolska, M. Z., \& Bidzan, M. (2011). Infertility as a psychological problem. Ginekologia Polska, 82, 44-49.

Radloff, L. S. (1977). The CES-D scale: A self-report depression scale for research in the general population. Applied Psychological Measurement, 1, 385-401. doi: 10.1177/014662167700100306

Revenson, T. A., \& DeLongis, A. (2011). Couples coping with chronic illness. In S. Folkman (ed.), The Oxford Handbook of Stress, Health, and Coping 
(pp. 101-123). New York, NY: Oxford University Press.

Ryff, C. D., \& Singer, B. (1998). The role of purpose in life and personal growth in positive human health. In P. T. P. Wong \& P. S. Fry (eds.), The human quest for meaning: A handbook of psychological research and clinical applications (pp. 213-235). Mahwah, NJ, US: Lawrence Erlbaum Associates Publishers.

Wang, M. C., Lightsey, O. R., Pietruszka, T., Uruk, A. C., \& Wells, A. G. (2007). Purpose in life and reasons for living as mediators of the relationship between stress, coping, and suicidal behavior. The Journal of Positive Psychology, 2, 195-204. doi: 10.1080/17439760701228920

Zegers-Hochschild, F., Adamson, G. D., de Mouzon, J., Ishihara, O., Mansour, R., Nygren, K., Sullivan, E., \& Vanderpoel, S.; World Health Organization. (2009). International Committee for Monitoring Assisted Reproductive Technology (ICMART) and the World Health Organization (WHO) revised glossary of ART terminology, 2009. Fertility and Sterility, 92, 1520-1524. doi: 10.1016/j.fertnstert.2009.09.009

Ziarko, M., Kaczmarek, Ł. D., \& Haładziński, P. (2013). Polish version of Centre for Epidemiological Studies Depression Scale (CES-D): results of a preliminary study on the psychometric properties of the scale. Current Issues in Personality Psychology, 1, 51-61. doi: 10.5114/cipp.2013.40637

Życińska, J., \& Januszek, M. (2011). Test Sensu Życia (Purpose in Life Test, PIL) J. C. Crumbaugha i L. T. Maholicka: analiza psychometryczna [Purpose in Life Test (PIL) J. C. Crumbaugh and L. T. Maholick: psychometric analysis]. Czasopismo Psychologiczne, 17, 133-142. 